\title{
PERENCANAAN ASUHAN KEPERAWATAN DI RUMAH SAKIT
}

\author{
Elisa Widyawati \\ elisawidyawati10@gmail.com
}

\section{LATAR BELAKANG}

Rumah sakit merupakan sebuah organisasi kesehatan yang sangat bermanfaat guna memberikan pelayanan kesehatan bagi masyarakat. Setiap tenaga kesehatan yang bekerja di Rumah Sakit harus bekerja sesuai dengan standar profesi, standar pelayanan rumah sakit, standar prosedur operasional yang berlaku, etika profesi, menghormati hak pasien, dan mengutamakan keselamatan pasien. Salah satu pelayanan kesehatan yang diberikan oleh tenaga kesehatan adalah pelayanan keperawatan, Sebagai bagian dari pelayanan kesehatan, maka pelayanan keperawatan yang dilakukan oleh tenaga perawat memiliki tugas diataranya memberikan asuhan keperawatan

Asuhan keperawatan adalah suatu pendekatan untuk pemecahan masalah yang memampukan perawat untuk mengatur dan memberikan asuhan keperawatan. Pelayanan asuhan keperawatan adalah suatu pendekatan dalam memberikan pelayanan dimana perawat berperan penting dalam proses memberikan jasa serta pelayanan yang baik terhadap pasien di rumah sakit. Standar asuhan keperawatan berfungsi sebagai pedoman maupun tolak ukur dalam pelaksanaan praktek keperawatan agar sesuai dengan nilai-nilai profesional, etika dan tanggung jawab. Penerapan standar asuhan keperawatan dalam hal ini meliputi standar pengkajian, diagnose keperawatan, intervensi, implementasi, evaluasi dan dokumentasi keperawatan tidak dilaksanakan dengan baik, hal ini mungkin berkaitan dengan faktor-faktor yang berhubungan dengan penerapan standar asuhan keperawatan. Proses keperawatan digunakan untuk membantu perawat melakukan praktik keperawatan yang terdiri dari lima tahap atau lima langkah, kelima langkah ini dilakukan berkesinambungan dengan melibatkan klien dan tenaga kesehatan lainnya. Penerapan proses keperawatan dalam asuhan keperawatan kepada klien merupakan tanggung jawab dan tanggung gugat perawat kepada klien. Pada akhirnya, penerapan proses keperawatan ini akan meningkatkan kualitas pelayanan keperawatan kepada klien. Pengkajian keperawatan dan perumusan diagnose keperawatan mengawali langkah perencanaan dari proses keperawatan. 
Perencanaan adalah kategori dari perilaku keperawatan dimana tujuan yang berpusat pada klien dan hasil yang diperkirakan ditetapkan dan intervensi keperawatan dipilih untuk mencapai tujuan tersebut. Selama perencanaan, dibuat prioritas. Perencanaan meliputi pengembangan strategi desain untuk mencegah, mengurangi, atau mengoreksi masalah-masalah yang telah diidentifikasi pada diagnose keperawatan. Tujuan perencanaan keperawatan adalah terpenuhinya kebutuhan klien.

\section{METODE}

Penerapan asuhan keperawatan di Rumah Sakit digunakan metode yakni teknik pengumpulan data dari berbagai sumber seperti textbook dan jurnal untuk mendapatkan data dan informasi yang lengkap dengan cara menyimpulkan dari 10jurnal dengan tahun paling tua 2012 . Dengan mencari dari berbagai jurnal maupun textbook dapat mudah dipahami dan dimengerti serta menyimpulkan nya dengan bahasa sendiri tanpa harus meniru karya orang lain.

\section{HASIL}

Pelayanan keperawatan merupakan bagian integral dari pelayanan kesehatan yang bisa menjadi tolak ukur keberhasilan dalam pencapaian tujuan suatu rumah sakit. Kualitas pelayanan keperawatan berjalan dengan baik apabila proses keperawatan yang dilaksanakan terstruktur dengan baik. Kualitas pelayanan ditentukan oleh manajemen asuhan keperawatan. Pelaksanakan asuhan keperawatan dengan menggunakan metode proses keperawatan untuk menyelesaikan masalah pasien, antara pasien dan perawat berhubungan secara langsung dalam pengelolaan asuhan keperawatan . Salah satu bentuk pelayanan keperawatan dalam rangka meningkatkan kualitas pelayanan adalah memberikan rasa tanggung jawab perawat yang lebih tinggi sehingga terjadi peningkatan kinerja kerja dan kepuasan pasien. Perawat yang memiliki kemampuan berpikir kritis akan menunjukkan sikap keberanian intelektual, berfikir terbuka, fleksibel, berfikir analisa, sistemasi, percaya diri, rasa ingin tahu, dewasa, kreatifitas, dan pemikiran mendalam. Penerapan asuhan keperawatan di Rumah Sakit merupakan suatu upaya dan tindakan dalam memberikan pelayanan yang baik terhadap pasien dimana dalam memberikan asuhan 
keperawatan perlu diperhatikan beberapa aspek sebelum melakukannya. Penerapan asuhan keperawatan oleh perawat pelaksana yang terdiri dari beberapa komponen yaitu: pengkajian keperawatan, diagnosa keperawatan, perencanaan keperawatan, implementasi dan evaluasi keperawatan. Dengan menerapakan asuhan keperawatan ini perawat harus mampu mengetahui masalah kondisi kesehatan pada pasien sebelum melakukan pengkajian terhadap pasien dengan begitu perawat dapat lebih mudah menerapkan system asuhan keperawatan yang harus diberikan terhadap klien saat berada di Rumah Sakit

Berdasarkan pecarian yang didapat menyatakan bahwa langkah-langkah perencanaan dalam proses keperawatan harus mempunyai beberapa komponen, yaitu

- Menentukan prioritas masalah

- Menuliskan tujuan dan kriteria hasil

- Memilih rencana intervensi atau tindakan keperawatan

- Melakukan pendokumentasian

\section{PEMBAHASAN}

Salah satu pelayanan kesehatan yang diberikan oleh tenaga kesehatan adalah pelayanan keperawatan, Sebagai bagian dari pelayanan kesehatan, maka pelayanan keperawatan yang dilakukan oleh tenaga perawatmemiliki tugas diataranya memberikan asuhan keperawatan . Asuhan keperawatan adalah suatu pendekatan untuk pemecahan masalah pada pasien dengan memberikan pelayanan keperawatan. Asuhan keperawatan dapat dipertanggungjawabkan berdasarkan substansi ilmiah yaitu logis, sistimatis, dinamis dan restruktur. Mutu asuhan keperawatan sangat dipengaruhi oleh kualitas pelayanan kesehatan dan bahkan sering menjadi salah satu faktor penentu citra institusi palayanan di mata masyarakat. Proses keperawatan adalah suattu metode ilmiah yang sistematis dan terorganisir dalam memberikan asuhan keperawatan pada pasien yang berfokus pada respon individu terhadap gangguan kesehatan yang di alami. Untuk menilai kualitas pelayanan keperawatan diperlukan adanya standar praktik keperawatan yang merupakan pedoman bagi perawat dalam melaksanakan asuhan keperawatan yang diwujudkan dalam bentuk proses keperawatan baik dari pengkajian sampai evaluasi. Standar asuhan yang tercantum dalam Standar Praktik Klinis Keperawatan terdiri dari lima fase 
asuhan keperawatan: 1) Pengkajian; 2) Diagnosa; 3) Perencanaan; 4) Implementasi; dan 5) Evaluasi. Standar asuhan keperawatan berfungsi sebagai pedoman maupun tolak ukur dalam pelaksanaan praktek keperawatan agar sesuai dengan nilai-nilai profesional, etika dan tanggung jawab.

Penerapan asuhan keperawatan adalah dimana tugas dan peran seorang perawat harus melakukan tahap-tahap dalam memberikan asuhan keperawatan pada pasien. Salah satu manfaat dari penerapan asuhan keperawatan yang baik adalah meningkatkan mutu dan kualitas pelayanan dalam bidang keperawatan. Penerapan asuhan keperawatan di Rumah Sakit merupakan suatu upaya dan tindakan dalam memberikan pelayanan yang baik terhadap pasien dimana dalam memberikan asuhan keperawatan perlu diperhatikan beberapa aspek sebelum melakukan nya. Dimana memberikan asuhan keperawatan peran dan tanggung jawab seorang perawat sangat penting untuk memberikan pelayanan yang berkualitas terhadap klien yang menerima pelayanan tersebut. Penerapan Asuhan Keperawatan oleh perawat pelaksana yang terdiri dari beberapa komponen yaitu: pengkajian keperawatan, diagnosa keperawatan, perencanaan keperawatan, implementasi dan evaluasi keperawatan. Pada penerapan asuhan keperawatan di Rumah Sakit masih mengalami beberapa kendala dimana perawat belum mengetahui standar prosedur yang harus dilakukan dalam memberikan asuhan keperawatan terhadap pasien. Permasalahan pelayanan keperawatan di negara Indonesia adalah banyaknya perawat yang belum melakukan asuhan keperawatan sesuai dengan standar. Hasil penelitian menunjukkan bahwa penerapan asuhan keperawatan dikatakan baik apabila perawat sudah melaksanakan tahaptahap dalam memberikan asuhan keperawatan kepada pasien yaitu: tahap pengkajian keperwatan, tahap diagnosa keperawatan, tahap perencanaan keperawatan, tahap implementasi keperawatan, dan tahap evaluasi keperawatan. Dimana dalam profesi keperawatan peran seorang perawat sebagai integral dari system pelayanan kesehatan.

\section{Tujuan Menetapkan Proses Keperawatan}

1) Pelaksanaan proses keperawatan secara umum bertujuan untuk menghasilkan asuhan keperawatan yang berkualitas

2) Tujuan penerapan proses keperawatan bagi klien, antara lain:

a) Mempertahankan kesehatan klien,

b) Mencegah sakit yang lebih parah/ penyebaran penyakit/ komplikasi akibat penyakit, 
c) Membantu pemulihan kondisi klien setelah sakit,

d) Mengembalikan fungsi maksimal tubuh, dan membantu klien terminal untuk meninggal dengan tenang.

Manfaat penggunaan proses keperawatan. Manfaatnya dapat dilihat dari sisi pelayanan kesehatan, pelaksanaan keperawatan, dan bagi klien atau pasien sendiri (Suarli \& Bahtiar, 2009).

Kualitas pelayanan yang baik akan meningkatkan kepuasan pasien dan keluarga demikian juga sebaliknya jika pasien dan keluarga tidak puas maka akan meninggalkan rumah sakit bila kualitas pelayanan buruk. Pelaksanakan asuhan keperawatan dengan menggunakan metode proses keperawatan untuk menyelesaikan masalah pasien, antara pasien dan perawat berhubungan secara langsung dalam pengelolaan asuhan keperawatan. Sistem pelayanan kesehatan mengharuskan adanya pendokumentasian karena dapat menjamin kelangsungan perawatan, dapat berfungsi sebagai bukti hukum dari proses perawatan dan mendukung evaluasi kualitas perawatan pasien, perawat yang kurang patuh dalam pendokumentasi asuhan keperawatan akan berakibat pada rendahnya mutu kelengkapan dokumentasi asuhan keperawatan.

Tujuan pengkajian adalah mendapatkan data dasar tentang kebutuhan, masalah kesehatan, pengalaman yang berkaitan, praktik kesehatan, tujuan, nilai dan gaya hidup yang dilakukan pasien. Kriteria pengkajian keperawatan meliputi: pertama pengumpulan data dilakukan dengan cara anamnesa, observasi, pemeriksaan fisik, serta pemeriksaan penunjang. Kedua, sumber data adalah pasien, keluarga atau orang yang terkait, tim kesehatan, rekam medik, dan catatan lain masa lalu, status kesehatan pasien saat ini, status bio, psiko, sosial spiritual, respon terhadap terapi. tahap pengkajian keperawatan perawat pelaksana sudah sangat baik dalam melakukan pengumpulan data, pengelompokan data, menganalisis data guna merumuskan diagnosis keperawatan. Hal tersebut dikarenakan perawat ruangan sangat paham mengenai pengkajian keperawatan maupun prosesnya. Hasil penelitian menunjukkan bahwa pada tahapan diagnosa keperawatan, perawat pelaksana telah mengklasifikasikan dan menganalisa data/hasil pengkajian keperawatan. Dimana perawat telah merumuskan suatu prioritas permaslahan pasien dengan baik. 
Metode Asuhan Keperawatan Terdapat beberapa metode pemberian asuhan keperawatan, yaitu

a. Metode kasus Metode kasus merupakan metode pemberian asuhan keperawatan yang pertama kali digunakan. Metode ini menggunakan satu perawat yang memberikan asuhan keperawatan kepada seorang klien secara total dalam satu periode dinas.

b. Metode fungsional Pemberian asuhan keperawatan pada metode fungsional ditekankan pada penyelesaian tugas dan prosedur. Setiap perawat diberi satu atau beberapa tugas untuk dilaksanakan kepada semua klien di suatu ruangan. Komunikasi antar perawat sangat terbatas sehingga tidak ada satu perawat yang mengetahui tentang satu klien secara komprehensif kecuali mungkin kepala ruangan. Keterbatasan itu sering menyebabkan klien merasa kurang puas terhadap layanan atau asuhan yang diberikan

c. Metode tim Metode tim merupakan metode pemberian asuhan keperawatan, yaitu seorang perawat professional memimpin sekelompok tenaga keperawatan dalam memberikan asuhan keperawatan pada sekelompok klien melalui upaya kooperatif dan kolaboratif

d. Metode keperawatan primer keperawatan primer merupakan suatu metode pemberian asuhan keperawatan, dimana terdapat hubungan yang dekat dan berkesinambungan antara klien dan seorang perawat tertentu yang bertanggungjawab dalam perencanaan, pemberian, dan koordinasi asuhan keperawatan klien, selama klien dirawat.

\section{Langkah-Langkah Perencanaan dalam Asuhan Keperawatan}

\section{Menentukan Prioritas Masalah}

Dalan menentukan perencanaan perlu disusun suatu sistematis untuk menentukan diagnosis yang akan pertama kali diintervensi. Secara realistis, perawat tidak dapat mengatasi semua diagnosis keperawatandan masalah kolaboratif yang terjadi kepada sebagian klien (individu), keluarga, dan masyarakat dengan mengidentifikasi prioritas diagnosis keperawatan dan masalah kolaboratif, perawat dapat memprioritaskan peralatan yang diperlukan.

\section{Menyusun Kriteria Hasil atau Tujuan}

Tujuan klien dan tujuan keperawatan merupakan standar atau ukuran yang digunakan untuk mengevaluasi kemajuan klien atau keterampilan perawat. Kriteria hasil (outcome) untuk 
diagnosis keperawatan mewakili status kesehatan klien dapat diubah atau dipertahankan melalui rencana asuhan keperawatan yang mandiri, sehingga dapat dibedakan antara diagnosis keperawatan dan masalah kolaboratif. Hasil dari diagnosis keperawatan tidak dapat membantu mengevaluasi efektivitas intervensi keperawatan jika tindakan medis juga diperlukan.

3. Memilih rencana intervensi atau tindakan keperawatan

Rencana intervensi keperawatan adalah desain spesifik dari intervensi yang disusun untuk membantu klien dan mencapai kriteria hasil. Perbedaan rencana intervensi keperawatan dan tindakan medis. Rencana intervensi keperawatan adalah rencana yang disusun perawat untuk kepentingan asuhan keperawatan yang akan digunakan oleh perawat yang menyusun maupun perawat lainnya. Sedangkan rencana tindakan medis difokuskan pada kegiatan yang berhubungan dengan diagnostik dan pengobatan (medikasi) berdasarkan kondisi klien. Tindakan tersebut didelegasikan kepada perawat dan profesi kesehatan lainnya.

\section{Karakteristik Rencana Asuhan Keperawatan}

a. Konsisten dengan rencana intervensi keperawatan.

b. Berdasarkan prinsip-prinsip ilmiah (rasional).

c. Berdasarkan kondisi klien (individu).

d. Digunakan untuk menciptakan suatu situasi yang aman dan terapeutik

e. Menciptakan suatu situasi pengajaran.

f. Menggunakan sarana yang sesuai.

\section{Melakukan pendokumentasian}

Format rencana asuhan keperawatan membantu perawat untuk memproses data yang diperoleh selama tahap pangkajian dan penegakan diagnosis keperawatan. Rencana asuhan keperawatan ditulis dalam suatu bentuk yang bervariasi guna mempromosikan perawatan yang meliputi perawatan individu, perawatan yang berkelanjutan, sebagai media komunikasi, dan evaluasi keberhasipan asuhan keperawatan. Setelah melakukan pengkajian, perawat harus mulai untuk mendokumentasikan diagnosis aktual atau risiko, kriteria hasil, dan rencana intervensi. 


\section{PENUTUP}

Proses keperawatan penting diterapkan dalam asuhan keperawatan. Asuhan keperawatan merupakan salah satu tindakan kunci dalam memberikan pelayanan kepada masyarakat ataupun pasien di Rumah Sakit. Rencana asuhan keperawatan yang disusun harus mempunyai beberapa komponen yaitu prioritas masalah, kriteria hasil, rencana intervensi dan pendokumentasian. Manfaat proses perencanaan keperawatan dapat memudahkan para petugas kesehatan untuk memberikan aasuhan keperawatan yang berkualitas. Dengan penerapan dan pelaksanaan asuhan keperawatan ini diharapkan perawat untuk terus melakukan pelatihan mengenai penerapan proses keperawatan di Rumah Sakit terhadap pasien untuk memberikan pelayanan yang bermutu dan bermanfaat serta memberikan system kerja pelayanan yang baik dan professional.

\section{DAFTAR PUSTAKA}

Abram B, Linnie, Lutfiani D,I. (2015). Gambaran Tingkat Pengetahuan Perawat dalam Penerapan Standar Asuhan Keperawatan Di Ruang Rawat Inap Interna RSUD Datoe Bhinangkang. E-Journal Keperawatan, Vol.3, No.3, 1-4.

Anggeria, E. Maria. (2018). Hubungan Supervisi dengan Pelaksanaan Asuhan Keperawatan. Jurnal Jumantik, Vol.3, No.2, 78-97.

Butar-Butar, J., \& Simamora, R. H. (2016). Hubungan Mutu Pelayanan Keperawatan dengan Tingkat Kepuasan Pasien Rawat Inap di RSUD Pandan Kabupaten Tapanuli Tengah. Jurnal Ners Indonesia, 6(1), 50-63.

Hidayah, N. (2014). Manajemen Model Asuhan Keperawatan Professional (MAKP) dalam Peningkatan Kepuasan Pasien di Rumah Sakit. Jurnal Kesehatan, Vol.7, No.2.

Husnul Wirdah, Yusuf M. (2017). Penerapan Asuhan Keperawatan oleh Perawat Pelaksana di Rumah Sakit Banda Aceh. Jurnal Keperawatan Indonesia, Vol.2, No.1, 1-7. 
Kasim, M., Abdurraouf, M. (2016). Peningkatan Kualitas Pelayanan dan pendokumentasikan Asuhan Keperawatan Dengan Metode TIM. Nurseline Journal, Vol.1, No.1, 62-72.

Mohammad iqbal, Hendro B, Jeavery. (2017). Pengaruh Manajemen Asuhan Keperawatan Profesional Tim Terhadap Kualitas Pelayanan Keperawatan Di RSUD Datoe Binangkang Kabupaten Bolaang Mongondow. e-Jurnal Keperawatan (eKP), Vol.5, No.2, 1-6.

Octy R.R, Tatiana Siregar. (2019). Hubungan Berpikir Kritis dengan Kepedulian Perawat dalam Melaksanakan Asuhan Keperawatan di RSUD Kota Depok. Jurnal Kedokteran dan Kesehatan, Vol.15, No.2.

Simamora, R. H. (2005). Hubungan Persepsi Perawat Pelaksana Terhadap Penerapan Fungsi Pengorganisasian Yang Dilakukan Oleh Kepala Ruangan Dengan Kinerjanya Diruang Rawat Inap RSUD Koja Jakarta Utara (Doctoral Dissertation, Tesis FIK UI, Tidak Dipublikasikan).

Sudono,B. Setya, D \& Atiningtyas, R. (2017). Gambaran Kemampuan Berpikir Kritis Perawat Primer dalam Pelaksanaan Asuhan Keperawatan di Rumah Sakit Islam Surakarta. Jurnal Ilmu Keperawatan Indonesia, Vol.10, No.1, 79-106.

Yanti. R.I., Warsito, B.E. (2013). Hubungan Karakteristik Perawat, Motivasi, dan Supervisi dengan Kualitas Dokumentasi Proses Asuhan Keperawatan. Jurnal Management Keperawatan, Vol.1, No.2, 107-114.

Yuyun P, Tri, Putri W. (2016). Faktor-Faktor Yang Berhubungan dengan Pendokumentasian Asuhan Keperawatan di Rumah Sakit Jiwa. Ners Jurnal Keperawatan, Vol.12, No.2, 131142. 